\title{
A systematic review about stablished methods and thresholds to determine velocity and accelerations in soccer
}

\section{Francisco J. Díaz-Soto}

University of Murcia

Markel Rico-González

University of the Basque Country, UPV-EHU

Luiz H. Palucci Vieira

UNESP São Paulo State University

Filipe Manuel Clemente

Instituto Politécnico de Viana do Castelo, Rua Escola Industrial e Comercial de Nun'Álvares

Hadi Nobari ( $\nabla$ hadi.nobari1@gmail.com )

University of Mohaghegh Ardabili

José Pino-Ortega

University of Murcia

\section{Research Article}

Keywords: team sport, data analysis, performance, high-intensity, speed

Posted Date: October 28th, 2021

DOl: https://doi.org/10.21203/rs.3.rs-983327/v1

License: (1) This work is licensed under a Creative Commons Attribution 4.0 International License.

Read Full License 


\section{Abstract \\ Background}

Velocity and accelerations have been highlighted as the most important variables in soccer. However, there is a consensus gap to define different levels of effort. The purpose of this systematic review is to identify those articles that purposed a threshold to establish (i) movement intensity at different velocities using tracking systems and (ii) accelerations using inertial measurement units, classifying the justification methods.

\section{Methods}

A systematic review of Cochrane Library, EBSCO, PubMed, Scielo, Scopus, SPORTDiscus, and Web of Science databases was performed according to the Preferred Reporting Items for Systematic Reviews and Meta-Analyses guidelines.

\section{Results}

From the 1983 studies initially identified, 40 were fully reviewed, and their outcome measures were extracted and analyzed.

\section{Conclusios:}

The $40 \mathrm{~m}$ maximal linear sprint test is the preferred method used in originating speed and acceleration thresholds in soccer despite recent research opted also to consider composite fitness measures such as anaerobic speed reserve. However, there is a substantial heterogeneity on locomotor testing procedures and workload zones established from these performance data while construct validity of several fitness indicators is not yet supported. Studies diverged on recommending, maybe consider or suggested avoid the use of individualized thresholds. Low sampling frequency ( $\leq 10 \mathrm{Hertz})$ in publications computing acceleration and deceleration demands should be also interpreted with caution. The present study collated evidence that may help conditioning professionals when processing and interpreting external load data in a soccer context.

\section{Background}

The soccer game is characterized by its intermittent regimen in periods of low-to-moderate intensity that are interspaced by high-intensity efforts [1]. Since the intermittent efforts, monitoring external load (or physical demands) of the players is not so simple as assessing the total distance covered [2]. In fact, as an intermittent running-based activity, the monitoring process of soccer is dependent on considering the intensity of running and the amount of time spent in different velocity thresholds [3]. This monitoring 
process helps coaches and sports scientists to identify the physical demands imposed by the match and to adjust the training load to the individual or collective needs of the players [4]. In fact, a proper individualization of the training stimulus will consider the specific demands of each player (mainly considering playing position), and to do that, specific information about physical demands in different intensity zones is required [5].

Usually, external load demands imposed by the match are assessed by microelectromechanical instruments, in which, global navigation satellite system, local position system, and/or inertial sensor units are the most popular and used [6]. These instruments allow controlling the displacement of players in a specific timeframe, thus allowing to measure not only the distances covered but also the velocity in which these distances are covered or the intensity of accelerations and decelerations during the movements performed [7]. Since the great amount of data generated, the definition of intensity zones become important, since coaches should consider the amount of low, moderate, or high demands for each player aiming to control not only the prevalent intensities but also the determinant ones [8].

As an example, although low-intensity running being prevalent in match scenarios, the most determinant running activities are related to the most intensity zones, namely considering the associations with specific player's performance or also using this information for controlling the injury risk [9]. Information about peak velocity, high speed running, or sprinting running has been used for managing training stimulus, implementing preventive training programs, or identifying mediators or moderators of injury [9, 10]. Therefore, establishing thresholds for running or acceleration/deceleration intensities are determinant.

The process of definition of thresholds is not easy and far to be the ideal. In fact, velocity thresholds can have a basis on the energetic systems and points of the threshold [11, 12]. However, this fact would lead to individual velocity thresholds for each player based on his capacity [13]. Despite such an approach, this is not easy to implement, and for that reason, standard velocity thresholds (for all players) are the most common practice in external load monitoring [14]. Despite this standardization for all players, the velocity thresholds vary from company to company or from study to study. This also increases the complexity of understanding variations in these demands between-players and contexts.

Due to a wide range of running and acceleration/deceleration thresholds used in the literature, it is important to summarize the evidence and provide recommendations for standardization in the future. This will improve the capacity of comparing results across different scenarios and generalize evidence. Although the importance of such summarization, as far we know no systematic review was conducted so far. Therefore, the purpose of this systematic review is to identify those articles that purposed a threshold to stablish (i) movement intensity at different velocities using tracking systems and (ii) accelerations using inertial measurement units, classifying the justification methods.

\section{Method}


The systematic review was reported in accordance with the Preferred Reporting Items for Systematic Reviews and Meta Analyses (PRISMA) guidelines [15] and methodology to conduct a systematic review of systematic reviews [16]. This review was not registered previously.

\subsection{Design}

The protocol was not registered prior to initiation of the project and did not require Institutional Review Board approval. A systematic search of five databases (i.e. PubMed, Web of Sciences, Cochrane Plus, Proquest, and Scopus) was performed by the authors to identify articles published before 16:00 p.m. on 5 October 2020. In all databases the search was limited to reviews. The authors were not blinded to journal names or manuscript authors. The PICO [15] design was used to provide an explicit statement of the question. Three main groups were created: (1) sport. soccer, football; (2) technology related words: GPS, "global positioning system*", LPS, "Local Positioning Systems", video, camera; (3) variables-related words: "physical performance", "running performance", "match running performance", "movement patterns", "time-motion analysis", "distances covered", "activity profile", "physical profile", "work rate", "match analysis", "match performance", "high intensity", acceleration, deceleration, thresholds, "training load", "acceleration profile", "acceleration zones", "acceleration thresholds", "velocity profile", "velocity thresholds", "velocity zones", "speed zones", "speed thresholds", "speed profile". The keywords were connected with AND to combine the three groups and using OR to link the words of each group.

\subsection{Screening strategy and study selection}

When the referred authors had completed the search (FDS, MRG), they compared their results to ensure that the same number of articles were found. Then, one of the authors downloaded the main data from the articles (title, authors, date, and database) to an Excel spreadsheet (Microsoft Excel, Microsoft, Redmond, USA) and removed the duplicate records. Subsequently, the same authors screened the remaining records to verify the inclusion-exclusion criteria (Table 1). 
Table 1

Inclusion/exclusion criteria

\begin{tabular}{|c|c|c|}
\hline $\begin{array}{l}\text { No } \\
\text { Criteria }\end{array}$ & Inclusion Criteria & Exclusion Criteria \\
\hline 1 & $\begin{array}{l}\text { Studies developed in } \\
\text { soccer }\end{array}$ & Studies conducted in other sports \\
\hline 2 & $\begin{array}{l}\text { Studies that identified } \\
\text { external training load } \\
\text { (velocity or accelerations). }\end{array}$ & $\begin{array}{l}\text { Studies that extracted external TL (not velocity or } \\
\text { accelerations) and internal TL. Also, studies not aimed to } \\
\text { extract TL. }\end{array}$ \\
\hline 3 & $\begin{array}{l}\text { Studies that provide } \\
\text { velocity and acceleration } \\
\text { threshold using EPTS or } \\
\text { IMU. }\end{array}$ & Studies that assess other technologies. \\
\hline 4 & $\begin{array}{l}\text { Only original and full-text } \\
\text { studies written in English }\end{array}$ & $\begin{array}{l}\text { Written in other language than English. Other article types } \\
\text { than original (e.g., reviews, letters to editors, trial } \\
\text { registrations, proposals for protocols, editorials, book } \\
\text { chapters and conference abstracts). }\end{array}$ \\
\hline 5 & $\begin{array}{l}\text { Justification of the } \\
\text { threshold by means of a } \\
\text { test, competition data or } \\
\text { other analysis techniques }\end{array}$ & Studies that did not justify the threshold used \\
\hline
\end{tabular}

\subsection{Data analysis}

All studies were summarised and then divided into groups depending on the classification type (i.e. velocity or acceleration). The values are presented in Table 2 and 3, extracting the following relevant information: EPTS used to data registration, manufacturer who belongs the used EPTS, branch, software in which efforts classification was made, sample, sex, level, task, and thresholds in speed categories. In additions, these studies were classified depending on the methods used to justify thresholds (e.g. test, maximum speed during training).

\subsection{Methodological Assessment}

Quality of studies was not assessed because aim of study was observational and therefore absolute values from articles were not considered. Therefore, as no quantitative results were included, no quality survey was utilised as scales of evaluation. All 39 articles outlined in Table 2 and 3 were assessed for suitability and evaluated by authors prior to inclusion. All studies had to meet all items on criteria list to be included in analysis.

\section{Results}




\subsection{Identification and selection of studies}

A total of 1982 (i.e. PubMed: 1228; WoK: 754) original articles were initially retrieved from the mentioned databases, of which 679 were duplicates. Thus, a total of 1303 original articles were found. The titles, abstracts and full texts of these works were checked, leading to the exclusion of $686,99,518,127,33$, and 319 by exclusion criteria number 1, 2, 3, 4, and 5, respectively. Thus, a total of 39 articles met all the inclusion criteria and were finally included in the qualitative synthesis (Figure 1).

\subsection{Study characteristics}

The characteristics of the studies included in the systematic review can be found in Table 2 and 3 (Table 2 and 3$)$.

\section{Discussion}

The main goal of the current work was to systematically review the scientific knowledge contained in peer-reviewed research articles that proposed threshold(s) used in establishing soccer players' movement intensity. A total of thirty-nine published papers addressing velocity and/or acceleration/deceleration bands respectively using tracking systems and inertial measurement were considered here. Based on these, our main collated findings were: (1) for either, velocity zones or acceleration demands, the preferred method to define intensity among studies was based on outcomes from $40 \mathrm{~m}$ sprint test, which was used in more than one-third of all literature covered in the searches; (2) the most frequent data collection systems employed to obtain external load measures were GPSs adjusted at a sampling frequency of 10 $\mathrm{Hz}(\sim 72 \%)$; these were also often used in creating the thresholds ( $41 \%) ;(3)$ nearly half of evidence is derived from youth male samples and during competitive matches; $(4)$ there was a predominant choice toward depicting movements solely in the meter unit ( $60 \%)$ and it is evident that the specific type of displacement recorded is unspecified in all excepting one work. Finally and of most importance to the current aim (5) it was not possible to identify a standardization in speed categories linked with distinct levels of movement given the wide discrepancies found across literature formulating individualized thresholds.

An important finding of this review study was that $40 \mathrm{~m}$ sprint test seemingly the most frequent procedure in establishing individualized speed thresholds in soccer. In fact, recommendations were formulated indicating that a $40 \mathrm{~m}$ path may be sufficient for players reaching their peak speed, being faster than in competitive matches and thereby possibly represent an adequate method of depicting players' external load [54]. Nevertheless, in none of the studies considering the $40 \mathrm{~m}$ sprint test either when evaluating players velocity [17-27] or accelerations/decelerations [11, 12, 52], there was a mention regarding its measurement properties (e.g. validity and reliability) for the specific population assessed while only three $[11,12,23]$ provided references which commented or directly determined a given of these aspects $(r=0.95-0.97 ; \mathrm{ICC}=0.94-0.99 ; \mathrm{TEE}=1.67-1.95 \%)[37,55]$. The transference of a locomotor testing outcome to match-play running performance is also critical when selecting appropriate testing 
tools. The so-called construct-or ecological-validity of the $40 \mathrm{~m}$ sprint test lacks consensus [see for a review: [56]] as reports are confirming its associations with match running performance [57] whilst no meaningful [37] or only position-dependent results were elsewhere observed [58]. One existing potential solution is the adoption of the maximal sprinting speed (MSS) [59] or a cluster technique using players' velocity samples [60] both obtained in the own matches, as input parameters to obtain thresholds. Yet only a few studies included here considered in-game MSS [47-49], and the clustering method was challenged [61]. Thus, despite gaining popularity to help individualize soccer demands, doubts may persist on the practical value of $40 \mathrm{~m}$ on-field sprinting test.

It is important to note that the individualization of thresholds may arguably benefit soccer practitioners. Examples include an a priori more accurate representation of player's demands experience in practice or match-play when using individualized thresholds. Enhanced ability in the management of individuals' workload will theoretically allow for the design of more effective recovery schedules and periodization training $[19,30,31,59]$. Also, the use of customized thresholds helps reduce high-speed running variability in either, within and between matches as well as from an individual or position-specific point of view [62]. On the other hand, some studies provided evidence that it can represent no additional value to the understanding of soccer external loads. The clearest example falls in the case of determining doseresponse to daily training routines. MSS in $40 \mathrm{~m}$ test routine showed impaired correlations with heart rate, ratings of perceived exertion [26] and wellness [27]. Furthermore, MSS is not necessarily higher in $40 \mathrm{~m}$ testing as compared to match-play outputs [63]. Most important, training-induced adaptations in running performance encountered during actual match-play are not always matched with those changes verified in $40 \mathrm{~m}$ sprint performance [64] whilst the frequency to which fitness components needs re-assessment, aiming at adjust thresholds accounting for those time-related changes, seemingly also unknown [65]. Collectively, such results reinforce the lack of full confidence and consensus in applying a $40 \mathrm{~m}$ linear sprint test as a way to obtain "anchors" of speed/acceleration thresholds. Soccer demands generally involve also energetic cost in changing direction, unorthodox displacements and physical impacts [27] which might be difficult to capture in common outcome metrics derived from traditional linear sprint tests.

In an attempt to overcome possible limitations of a single bout maximal linear sprint as mentioned above, also considering the lowest weight it may have to a dataset of soccer external load measures collected in official matches [66] likely given the one-off nature of MSS in soccer [67], some authors employed test protocols more prolonged in nature. These included Yo-Yo Intermittent Recovery Test level 1, Vam-Eval maximal incremental running test, $30: 15$ Intermittent Fitness test $\left(30-15_{\mathrm{IFT}}\right)$ and Conconi test performed on a treadmill. Despite having large-to-very large associations with match-play running performance either relating to the total distance covered or high-intensity running [56], graded exhaustive treadmill tests represent serious limitations to most clubs given time requirements, costs and players motivation implying a need to consider other solutions with more prominent practical value such as fieldbased assessments [68]. Instead, a trend of a recent increase in the use of anaerobic speed reserve (ASR) as a threshold was noted here for approximately one-fourth of all studies included of which most were 
published over the last three years $[20,27,35,36,38,39,42]$. The ASR is a compound of two markers, i.e. computed as the difference between player MSS and maximal aerobic speed thus combining in a single index the individual's fitness characteristics observed on a separate all-out sprint effort and those from $\mathrm{vVO}_{2 \text { max }}$. Such metric seemingly of benefit in creating thresholds since players showing similar $\mathrm{vVO}_{2 \max }$ (not uncommon across outfield playing positions; [69]) may not have a matched MSS performance $[57,70]$. In this conditions, ability to cope with a given load, in particular at high-intensity domain, would depends on the proportion of ASR reached [71] rather than looking solely for a percentage of the former fitness indicator. Again, one of the issues which arguably preclude unrestricted recommendation of ASR to date is none empirical evidence supporting its construct validity (e.g. $30-15_{\mathrm{IFT}}$ performance versus match-play running outputs; see also [72]).

Regardless of whether there is currently an unsolved debate, since studies recommend using $[54,62,73]$, maybe $[19,65,74]$ or others suggest avoid $[26,56,59]$ fitness testing when defining speed thresholds, a lack of standardization was observed here in both, determinations of individualized speed/acceleration categories representing distinct workload demands and the parameters used to extract a given anchor. To be explicit and using the $40 \mathrm{~m}$ sprint test as an example, timing gates at the start, 10 and $40 \mathrm{~m}$ [22]; 30 and $40 \mathrm{~m}$ [21]; 10-m intervals [17-20, 26, 27]; or MSS attained independent of location [23, 24, 52] were among methods used. Furthermore, following these procedures, the levels for "higher" intensity recorded were defined considering 50-60\% [52], 80-100\% [19, 20], >61\% [17, 18, 21], >65\% [26], >75\% [22], >80\% $[23,24,27]$ or $>90 \%[52]$ of MSS. It makes it difficult to directly compare results across literature and provide systematic concluding remarks on the most appropriate one. To assist move beyond on this question, intervention designs assessing the practical effect of individualized thresholds in various aspects (e.g. fitness, injury and match performance) are recommended as opposed to common application/comparison of methods [73].

Finally, particular attention should be also paid to the technology employed in obtaining performance indices often used in originating the movement intensity thresholds. Ten-hertz GPS were identified as the most common devices used in both, determination of velocity/acceleration thresholds during testing routines and collection of task external loads. It is recognized that these generally provide valid measures to assess distance and velocity in linear movements and during simulations of running characteristics pertaining to team sports while no additional benefits of a nearby higher acquisition frequency can exist $[6,75]$. However, during acceleration occurrences above $4 \mathrm{~m} / \mathrm{s}^{2}$ limits, accuracy using $10 \mathrm{~Hz}$ GPS is not always ensured [76]. One can argue that there is not a true 'gold standard' available in computing external load such as running performance $[17,77,78]$ while others recognize high-speed three-dimensional motion capture systems [6]. Context, logistics and the need for a qualified team that has the how-to for data treatment of image sequences are among potential constraints on the use of the latter. Examples include respectively the costs involved, set-up configuration and time-consuming nature which collectively make difficult application of video-based tracking systems in practice. This is also observed in the present analysis owing that only one study using the latter method was found (see Table 2). Regardless of which EPTS or IMU are used, one further point requiring more caution is the fact that 
measurement error should be ideally evaluated considering the specific location they were collected [see for a review: [59]], and only 2 studies included in our analysis did it such way [47, 48]; most cited data from previous investigations or reported just the horizontal dilution of precision calculated by the proprietary software. In sum, interpreting current evidence on speed but not acceleration thresholds using $10 \mathrm{~Hz}$ GPS may be reliable, and quality-control experiments are still needed within original investigations.

\section{Limitations}

A number of potential limitations should be recognized to the methods used in the present review as well as the derived implications: (1) inclusion of studies only in English, which may have resulted in a loss of evidence on the topic when published in other language; (2) consideration of all works regardless of whether it varies concerning the quality of evidence; (3) lack of a quantitative synthesis of extracted information, which is partly attributed to a substantial heterogeneity of methods used across included articles; (4) only 8 studies [17, 27, 30-32, 37, 45, 46, 48] were conducted with a minimum of 80 players as per previous recommendations to ensure sufficient statistical power [79]; (5) evidence may apply to a greater extent to youth male players rather than senior male and women's soccer and finally (6) despite the probed importance of curvilinear movements [80], these were not specifically determined in any of the reviewed studies.

\section{Conclusion}

In short, $40 \mathrm{~m}$ sprint test performed on-field was identified here as the preferred method to create individualized speed or acceleration thresholds in depicting players' external load in soccer. While the benefits of drawing thresholds from a single fitness indicator such as maximal sprinting performance are evidently accompanied by a number of limitations (e.g. may lack superior sensitivity to profile doseresponse to training-induced changes), a rapid increase was identified in recent years suggesting the use of compound measures such as anaerobic speed reserve. However, in either case, the construct validity of fitness data to predict match-play running performance is not supported up to date. Also, the lack of standardization on test procedures and threshold zones established as well as the low sampling frequency in studies computing acceleration and deceleration demands defy practical applications. Finally, extending previous research using match data to obtain thresholds is still required aiming at overcome potential issues incurring from testing outside game context, otherwise intervention works are needed to confirm the value of individualisations based on fitness status.

\section{Abbreviations}

ASR $=$ Anaerobic speed reserve

EPTS: Electronic performance and tracking systems

GPS = Global positioning system 
LPS $=$ Local Positioning Systems

MSS $=$ Maximal sprinting speed

PRISMA = Preferred reporting items for systematic reviews and meta analyses

\section{Declarations}

\section{Ethics Approval and Consent to Participate}

Not applicable.

\section{Consent for Publication}

Not applicable.

\section{Availability of Data and Materials}

Not applicable.

\section{Competing Interests}

The authors declare that they have no competing interests relevant to the content of this article.

\section{Funding}

No funding was obtained for this study

\section{Authors' Contributions}

FDS, MRG, and JPO made substantial contributions to the conception of the manuscript. FDS, MRG, LPV, FMC, HN, and JPO, drafted, revised and approved the final version.

\section{Acknowledgements}

Not applicable.

\section{References}

1. Dolci F, Hart NH, Kilding AE, Chivers P, Piggott B, Spiteri T. Physical and Energetic Demand of Soccer: A Brief Review. Strength and Conditioning Journal. 2020;00:8.

2. Hader K, Rumpf MC, Hertzog M, Kilduff LP, Girard O, Silva JR. Monitoring the Athlete Match Response: Can External Load Variables Predict Post-match Acute and Residual Fatigue in Soccer? A Systematic Review with Meta-analysis. Sports Med - Open. 2019;5:48. 
3. Castagna C, Varley M, Póvoas SCA, D'Ottavio S. Evaluation of the Match External Load in Soccer: Methods Comparison. International Journal of Sports Physiology and Performance. 2017;12:490-5.

4. Buchheit M. Managing high-speed running load in professional soccer players: The benefit of highintensity interval training supplementation. 2019.

5. Beato M, Drust $B$, lacono AD. Implementing High-speed Running and Sprinting Training in Professional Soccer. Int J Sports Med. 2020;a-1302-7968.

6. Crang ZL, Duthie G, Cole MH, Weakley J, Hewitt A, Johnston RD. The Validity and Reliability of Wearable Microtechnology for Intermittent Team Sports: A Systematic Review. Sports Med. 2021;51:549-65.

7. Whitehead S, Till K, Weaving D, Jones B. The Use of Microtechnology to Quantify the Peak Match Demands of the Football Codes: A Systematic Review. Sports Med. 2018;48:2549-75.

8. Reinhardt L, Schwesig R, Lauenroth A, Schulze S, Kurz E. Enhanced sprint performance analysis in soccer: New insights from a GPS-based tracking system. Marocolo M, editor. PLoS ONE. 2019;14:e0217782.

9. Malone S, Owen A, Mendes B, Hughes B, Collins K, Gabbett TJ. High-speed running and sprinting as an injury risk factor in soccer: Can well-developed physical qualities reduce the risk? Journal of Science and Medicine in Sport. 2018;21:257-62.

10. Buchheit M, Simpson BM, Hader K, Lacome M. Occurrences of near-to-maximal speed-running bouts in elite soccer: insights for training prescription and injury mitigation. Science and Medicine in Football. 2020;1-6.

11. Abbott W, Brickley G, Smeeton NJ. An individual approach to monitoring locomotive training load in English Premier League academy soccer players. International Journal of Sports Science \& Coaching. 2018;13:421-8.

12. Abbott W, Brickley G, Smeeton NJ, Mills S. Individualizing Acceleration in English Premier League Academy Soccer Players. Journal of Strength and Conditioning Research. 2018;32:3503-10.

13. Abt G, Lovell R. The use of individualized speed and intensity thresholds for determining the distance run at high-intensity in professional soccer. Journal of Sports Sciences. 2009;27:893-8.

14. Jastrzębski Z, Radzimiński Ł. Default and individual comparison of physiological responses and time-motion analysis in male and female soccer players during small-sided games. jhse [Internet]. 2017 [cited 2020 Oct 25];12. Available from: http://hdl.handle.net/10045/71950

15. Moher D, Liberati A, Tetzlaff J, Altman DG. Preferred Reporting Items for Systematic Reviews and Meta-Analyses: The PRISMA Statement. PLoS Medicine. 2009;6:6.

16. Smith V, Devane D, Begley CM, Clarke M. Methodology in conducting a systematic review of systematic reviews of healthcare interventions. BMC Med Res Methodol. 2011;11:15.

17. Buchheit M, Mendez-villanueva A, Simpson BM, Bourdon PC. Repeated-Sprint Sequences During Youth Soccer Matches. Int J Sports Med. 2010;31:709-16. 
18. Scantlebury S, Till K, Beggs C, Dalton-Barron N, Weaving D, Sawczuk T, et al. Achieving a desired training intensity through the prescription of external training load variables in youth sport: More pieces to the puzzle required. Journal of Sports Sciences. 2020;38:1124-31.

19. Hunter F, Bray J, Towlson C, Smith M, Barrett S, Madden J, et al. Individualisation of Time-Motion Analysis: A Method Comparison and Case Report Series. Int J Sports Med. 2014;36:41-8.

20. Tomazoli G, Marques JB, Farooq A, Silva JR. Estimating Postmatch Fatigue in Soccer: The Effect of Individualization of Speed Thresholds on Perceived Recovery. International Journal of Sports Physiology and Performance. 2020;15:1216-22.

21. Sparks M, Coetzee B, Gabbett TJ. INTERNAL AND EXTERNAL MATCH LOADS OF UNIVERSITY-LEVEL SOCCER PLAYERS: A COMPARISON BETWEEN METHODS. 2017;6.

22. Meylan C, Trewin J, McKean K. Quantifying Explosive Actions in International Women's Soccer. International Journal of Sports Physiology and Performance. 2017;12:310-5.

23. Zurutuza U, Castellano J, Echeazarra I, Guridi I, Casamichana D. Selecting Training-Load Measures to Explain Variability in Football Training Games. Front Psychol. 2020;10:2897.

24. Zurutuza U, Castellano J, Echeazarra I, Casamichana D. Absolute and Relative Training Load and Its Relation to Fatigue in Football. Front Psychol. 2017;8:878.

25. Núñez-Sánchez FJ, Toscano-Bendala FJ, Campos-Vázquez MA, Suarez LJ. Individualized speed threshold to analyze the game running demands in soccer players using GPS technology Umbral de velocidad individualizado para analizar en jugadores de fútbol mediante tecnología GPS las exigencias de sus desplazamientos en competición. 2017;4.

26. Scott $D$, Lovell R. Individualisation of speed thresholds does not enhance the dose-response determination in football training. Journal of Sports Sciences. 2018;36:1523-32.

27. Scott D, Norris D, Lovell R. Dose-Response Relationship Between External Load and Wellness in Elite Women's Soccer Matches: Do Customized Velocity Thresholds Add Value? International Journal of Sports Physiology and Performance. 2020;15:1245-51.

28. Doncaster G, Unnithan V. Between-Game Variation of Physical Soccer Performance Measures in Highly Trained Youth Soccer Players: Journal of Strength and Conditioning Research. 2019;33:191220.

29. Doncaster G, Marwood S, Iga J, Unnithan V. Influence of oxygen uptake kinetics on physical performance in youth soccer. Eur J Appl Physiol. 2016;116:1781-94.

30. Atan SA, Foskett A, Ali A. Motion Analysis of Match Play in New Zealand U13 to U15 Age-Group Soccer Players: Journal of Strength and Conditioning Research. 2016;30:2416-23.

31. Harley JA, Barnes CA, Portas M, Lovell R, Barrett S, Paul D, et al. Motion analysis of match-play in elite U12 to U16 age-group soccer players. Journal of Sports Sciences. 2010;28:1391-7.

32. Saward C, Morris JG, Nevill ME, Nevill AM, Sunderland C. Longitudinal development of matchrunning performance in elite male youth soccer players: Match-running performance in youth soccer. Scand J Med Sci Sports. 2016;26:933-42. 
33. Tan D, Dawson B, Peeling P. Hemolytic Effects of a Football-Specific Training Session in Elite Female Players. International Journal of Sports Physiology and Performance. 2012;7:271-6.

34. Nakamura FY, Pereira LA, Loturco I, Rosseti M, Moura FA, Bradley PS. Repeated-Sprint Sequences During Female Soccer Matches Using Fixed and Individual Speed Thresholds: Journal of Strength and Conditioning Research. 2017;31:1802-10.

35. Rago V, Brito J, Figueiredo P, Krustrup P, Rebelo A. Application of Individualized Speed Zones to Quantify External Training Load in Professional Soccer. Journal of Human Kinetics. 2020;72:11.

36. Rago V, Brito J, Figueiredo P, Krustrup P, Rebelo A. Relationship between External Load and Perceptual Responses to Training in Professional Football: Effects of Quantification Method. Sports. 2019;7:68.

37. Mendez-Villanueva A, Buchheit M, Simpson B, Bourdon P. Match Play Intensity Distribution in Youth Soccer. Int J Sports Med. 2012;34:101-10.

38. Abbott W, Brickley G, Smeeton NJ. Physical demands of playing position within English Premier League academy soccer. jhse [Internet]. 2018 [cited 2020 Nov 10];13. Available from: http://hdl.handle.net/10045/74375

39. Abbott W, Brickley G, Smeeton NJ. Positional Differences in GPS Outputs and Perceived Exertion During Soccer Training Games and Competition: Journal of Strength and Conditioning Research. 2018;32:3222-31.

40. Skalska M, Nikolaidis PT, Knechtle B, Rosemann TJ, Radzimiński $Ł$, Jastrzębska J, et al. Vitamin D Supplementation and Physical Activity of Young Soccer Players during High-Intensity Training. Nutrients. 2019;11:349.

41. Jastrzębski Z, Radzimiński Ł. Individual vs General Time-Motion Analysis and Physiological Response in 4 vs 4 and 5 vs 5 Small-Sided Soccer Games. International Journal of Performance Analysis in Sport. 2015;15:397-410.

42. Trewin J, Meylan C, Varley MC, Cronin J. The match-to-match variation of match-running in elite female soccer. Journal of Science and Medicine in Sport. 2018;21:196-201.

43. Buchheit M, Hammond K, Bourdon PC, Simpson BM, Garvican LA, Schmidt WF, et al. Relative Match Intensities at High Altitude in Highly-Trained Young Soccer Players (ISA3600). 2015;5.

44. Madison G, Patterson SD, Read P, Howe L, Waldron M. EFFECTS OF SMALL-SIDED GAME VARIATION ON CHANGES IN HAMSTRING STRENGTH. 2019;7.

45. Goto H, Morris JG, Nevill ME. Motion analysis of U11 to U16 elite English Premier League Academy players. Journal of Sports Sciences. 2015;33:1248-58.

46. Goto H, Morris JG, Nevill ME. Influence of Biological Maturity on the Match Performance of 8- to 16Year-Old, Elite, Male, Youth Soccer Players: Journal of Strength and Conditioning Research. 2019;33:3078-84.

47. Aquino R, Melli-Neto B, Ferrari JVS, Bedo BLS, Vieira LHP, Santiago PRP, et al. Validity and reliability of a 6-a-side small-sided game as an indicator of match-related physical performance in elite youth Brazilian soccer players. Journal of Sports Sciences. 2019;37:2639-44. 
48. Palucci Vieira LH, Aquino R, Moura FA, Barros RML de, Arpini VM, Oliveira LP, et al. Team Dynamics, Running, and Skill-Related Performances of Brazilian U11 to Professional Soccer Players During Official Matches: Journal of Strength and Conditioning Research. 2019;33:2202-16.

49. Springham M, Williams S, Waldron M, Strudwick AJ, Mclellan C, Newton RU. Prior workload has moderate effects on high-intensity match performance in elite-level professional football players when controlling for situational and contextual variables. Journal of Sports Sciences. 2020;38:2279-90.

50. Vigne G, Gaudino C, Rogowski I, Alloatti G, Hautier C. Activity Profile in Elite Italian Soccer Team. Int J Sports Med. 2010;31:304-10.

51. Beato M, Drust B. Acceleration intensity is an important contributor to the external and internal training load demands of repeated sprint exercises in soccer players. Research in Sports Medicine. 2020;1-10.

52. Núñez FJ, Toscano-Bendala FJ, Suarez-Arrones L, Martínez-Cabrera FI, De Hoyo M. Individualized thresholds to analyze acceleration demands in soccer players using GPS (Umbrales individualizados para analizar las demandas en la aceleración en futbolistas usando GPS). Retos. 2018;75-9.

53. Serpiello F, Duthie G, Moran C, Kovacevic D, Selimi E, Varley M. The Occurrence of Repeated High Acceleration Ability (RHAA) in Elite Youth Football. Int J Sports Med. 2018;39:502-7.

54. Kyprianou E, Di Salvo V, Lolli L, Al Haddad H, Villanueva AM, Gregson W, et al. To Measure Peak Velocity in Soccer, Let the Players Sprint. J Strength Cond Res. 2019;

55. Roe G, Darrall-Jones J, Black C, Shaw W, Till K, Jones B. Validity of 10-HZ GPS and Timing Gates for Assessing Maximum Velocity in Professional Rugby Union Players. Int J Sports Physiol Perform. 2017;12:836-9.

56. Aquino R, Carling C, Maia J, Vieira LHP, Wilson RS, Smith N, et al. Relationships between running demands in soccer match-play, anthropometric, and physical fitness characteristics: a systematic review. International Journal of Performance Analysis in Sport. Routledge; 2020;20:534-55.

57. Al Haddad H, Simpson BM, Buchheit M, Di Salvo V, Mendez-Villanueva A. Peak match speed and maximal sprinting speed in young soccer players: effect of age and playing position. Int $J$ Sports Physiol Perform. 2015;10:888-96.

58. Buchheit M, Mendez-Villanueva A, Simpson BM, Bourdon PC. Match running performance and fitness in youth soccer. Int J Sports Med. 2010;31:818-25.

59. Palucci Vieira LH, Carling C, Barbieri FA, Aquino R, Santiago PRP. Match Running Performance in Young Soccer Players: A Systematic Review. Sports Med. 2019b;49:289-318.

60. Park LAF, Scott D, Lovell R. Velocity zone classification in elite women's football: where do we draw the lines? Science and Medicine in Football. Routledge; 2019;3:21-8.

61. Vescovi JD. Women's soccer velocity thresholds: statistical techniques or physiological metrics context is critical. Science and Medicine in Football. Routledge; 2019;3:81-2.

62. Carling C, Bradley P, McCall A, Dupont G. Match-to-match variability in high-speed running activity in a professional soccer team. Journal of Sports Sciences. Routledge; 2016;34:2215-23. 
63. Massard T, Eggers T, Lovell R. Peak speed determination in football: is sprint testing necessary? Science and Medicine in Football. Routledge; 2018;2:123-6.

64. Buchheit M, Simpson BM, Mendez-Villanueva A. Repeated high-speed activities during youth soccer games in relation to changes in maximal sprinting and aerobic speeds. Int $\mathrm{J}$ Sports Med. 2013;34:40-8.

65. Drust B. An individual approach to monitoring locomotive training load in English Premier League academy soccer players. International Journal of Sports Science \& Coaching. SAGE Publications; 2018;13:429-30.

66. Casamichana D, Castellano J, Gómez Díaz A, Martín-García A. Looking for Complementary Intensity Variables in Different Training Games in Football. J Strength Cond Res. 2019;

67. Carling C, McCall A, Harper D, Bradley PS. Comment on: "The Use of Microtechnology to Quantify the Peak Match Demands of the Football Codes: A Systematic Review." Sports Med. 2019;49:343-5.

68. Buchheit M, Simpson BM, Lacome M. Monitoring Cardiorespiratory Fitness in Professional Soccer Players: Is It Worth the Prick? Int J Sports Physiol Perform. 2020;1-5.

69. Slimani M, Znazen H, Miarka B, Bragazzi NL. Maximum Oxygen Uptake of Male Soccer Players According to their Competitive Level, Playing Position and Age Group: Implication from a Network Meta-Analysis. J Hum Kinet. 2019;66:233-45.

70. Djaoui L, Chamari K, Owen AL, Dellal A. Maximal Sprinting Speed of Elite Soccer Players During Training and Matches. The Journal of Strength \& Conditioning Research. 2017;31:1509-17.

71. Buchheit M, Laursen PB. High-intensity interval training, solutions to the programming puzzle: Part l: cardiopulmonary emphasis. Sports Med. 2013;43:313-38.

72. Čović N, Jelešković E, Alić H, Rađo I, Kafedžić E, Sporiš G, et al. Reliability, Validity and Usefulness of 30-15 Intermittent Fitness Test in Female Soccer Players. Front Physiol [Internet]. Frontiers; 2016 [cited $2021 \mathrm{Feb} 27] ; 7$. Available from: https://www.frontiersin.org/articles/10.3389/fphys.2016.00510/full

73. Kavanagh R, Carling C. Analysis of external workload in soccer training and competition: generic versus individually determined speed thresholds. Science and Medicine in Football. Routledge; 2019;3:83-4.

74. Weston M. Difficulties in Determining the Dose-Response Nature of Competitive Soccer Matches. J Athl Enhancement [Internet]. 2013 [cited 2021 Mar 6];02. Available from: http://www.scitechnol.com/2324-9080/2324-9080-2-e107.php

75. Scott MTU, Scott TJ, Kelly VG. The Validity and Reliability of Global Positioning Systems in Team Sport: A Brief Review. The Journal of Strength \& Conditioning Research. 2016;30:1470-90.

76. Akenhead R, French D, Thompson KG, Hayes PR. The acceleration dependent validity and reliability of $10 \mathrm{~Hz}$ GPS. Journal of Science and Medicine in Sport. 2014;17:562-6.

77. Carling C, Bloomfield J, Nelsen L, Reilly T. The role of motion analysis in elite soccer: contemporary performance measurement techniques and work rate data. Sports Med. 2008;38:839-62. 
78. Lovell R, Barrett S, Portas M, Weston M. Re-examination of the post half-time reduction in soccer work-rate. Journal of Science and Medicine in Sport. 2013;16:250-4.

79. Gregson W, Drust B, Atkinson G, Salvo VD. Match-to-match variability of high-speed activities in premier league soccer. Int J Sports Med. 2010;31:237-42.

80. Granero-Gil P, Bastida-Castillo A, Rojas-Valverde D, Gómez-Carmona CD, de la Cruz Sánchez E, PinoOrtega J. Influence of Contextual Variables in the Changes of Direction and Centripetal Force Generated during an Elite-Level Soccer Team Season. International Journal of Environmental Research and Public Health. Multidisciplinary Digital Publishing Institute; 2020;17:967.

\section{Tables}

Due to technical limitations, Table 2 and 3 is only available as a download in the Supplemental Files section.

\section{Figures}



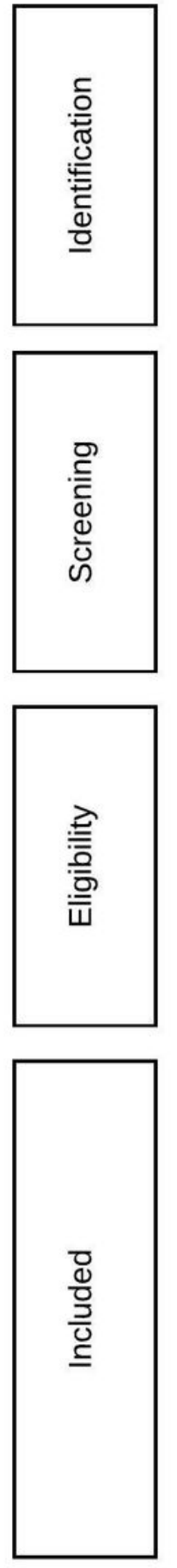

Records identified through database searching

$(n=1982)$
Additional records identified through other sources

$$
(n=0)
$$
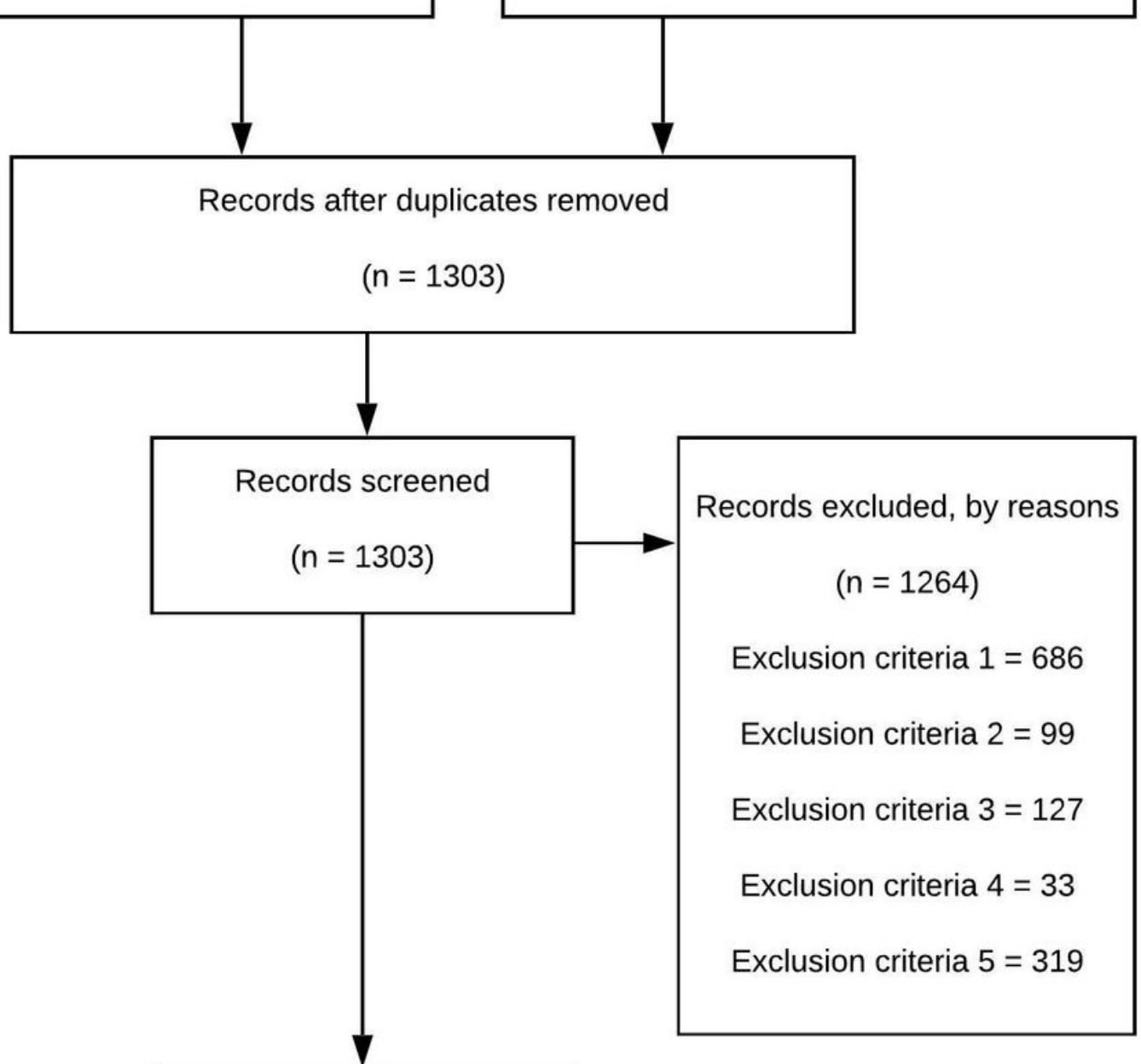

Studies included in qualitative synthesis

$(n=39)$

\section{Figure 1}

Flow diagram of the selection of studies.

\section{Supplementary Files}

This is a list of supplementary files associated with this preprint. Click to download.

- Table2.docx 
- Table3.docx

Page 18/18 